\title{
Genetic Variation of Flavonols Quercetin, Myricetin, and Kaempferol in the Sri Lankan Tea (Camellia sinensis L.) and Their Health-Promoting Aspects
}

\author{
Brasathe Jeganathan, ${ }^{1}$ P. A. Nimal Punyasiri, ${ }^{2}$ J. Dananjaya Kottawa-Arachchi, ${ }^{3}$ \\ Mahasen A. B. Ranatunga, ${ }^{3}$ I. Sarath B. Abeysinghe, ${ }^{3}$ \\ M. T. Kumudini Gunasekare, ${ }^{4}$ and B. M. Ratnayake Bandara ${ }^{5}$ \\ ${ }^{1}$ Department of Food Science and Technology, Faculty of Agriculture, University of Peradeniya, Peradeniya, Sri Lanka \\ ${ }^{2}$ Institute of Biochemistry Molecular Biology and Biotechnology, University of Colombo, 00300 Colombo, Sri Lanka \\ ${ }^{3}$ Tea Research Institute of Sri Lanka, Talawakelle, Sri Lanka \\ ${ }^{4}$ Coordinating Secretariat for Science, Technology \& Innovation, 3rd Floor, Standard Charted Building, \\ Janadhipathi Mawatha, 00100 Colombo, Sri Lanka \\ ${ }^{5}$ Department of Chemistry, Faculty of Science, University of Peradeniya, Peradeniya, Sri Lanka
}

Correspondence should be addressed to P. A. Nimal Punyasiri; nimal@ibmbb.cmb.ac.lk

Received 27 March 2016; Accepted 9 May 2016

Academic Editor: Rong Di

Copyright (C) 2016 Brasathe Jeganathan et al. This is an open access article distributed under the Creative Commons Attribution License, which permits unrestricted use, distribution, and reproduction in any medium, provided the original work is properly cited.

Flavonol glycosides in tea leaves have been quantified as aglycones, quercetin, myricetin, and kaempferol. Occurrence of the said compounds was reported in fruits and vegetable for a long time in association with the antioxidant potential. However, data on flavonols in tea were scanty and, hence, this study aims to envisage the flavonol content in a representative pool of accessions present in the Sri Lankan tea germplasm. Significant amounts of myricetin, quercetin, and kaempferol have been detected in the beverage type tea accessions of the Sri Lankan tea germplasm. This study also revealed that tea is a good source of flavonol glycosides. The Camellia sinensis var. sinensis showed higher content of myricetin, quercetin, and total flavonols than var. assamica and ssp. lasiocalyx. Therefore flavonols and their glycosides can potentially be used in chemotaxonomic studies of tea germplasm. The nonbeverage type cultivars, especially Camellia rosaflora and Camellia japonica Red along with the exotic accessions resembling China type, could be useful in future germplasm studies because they are rich sources of flavonols, namely, quercetin and kaempferol, which are potent antioxidants. The flavonol profiles can be effectively used in choosing parents in tea breeding programmes to generate progenies with a wide range of flavonol glycosides.

\section{Introduction}

Tea is the second most popular beverage after water which represents a major source of dietary polyphenols [1]. Thus the scientific community is interested in exploring the healthpromoting constituents present in tea, namely, flavan-3-ols, flavonols, and their derivatives [2]. Recent epidemiological studies have demonstrated a protective effect of fruits and vegetables against the incidence of degenerative diseases [3]. Several classes of compounds have been assumed as potential protective factors, one of which is the flavonoids, generally considered as nonnutritive agents. Flavonoids are known as secondary metabolites which are the largest class of polyphenols widely distributed in the plant kingdom. It can be subdivided into six major subclasses based on the structural variations: flavones, flavanones, isoflavones, flavonols, flavanols, and anthocyanidins [4].

According to the study conducted by Hollman et al. [5] tea is a good source of flavonols. Flavonols have recently received much attention due to their antioxidant, antimicrobial, anticancer, antiatherosclerotic, and antiproliferative properties [6-8]. The flavonols exist in tea plant (Camellia sinensis L.) 


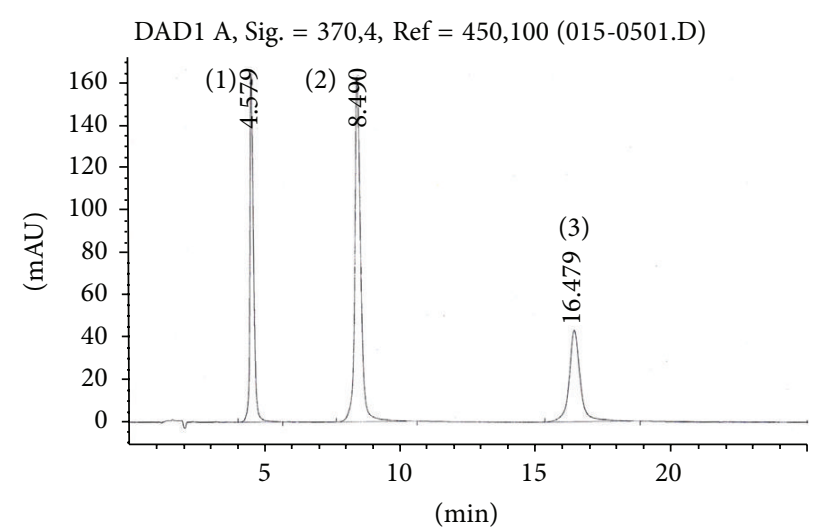

(1) Myricetin

(2) Quercetin

(3) Kaempferol

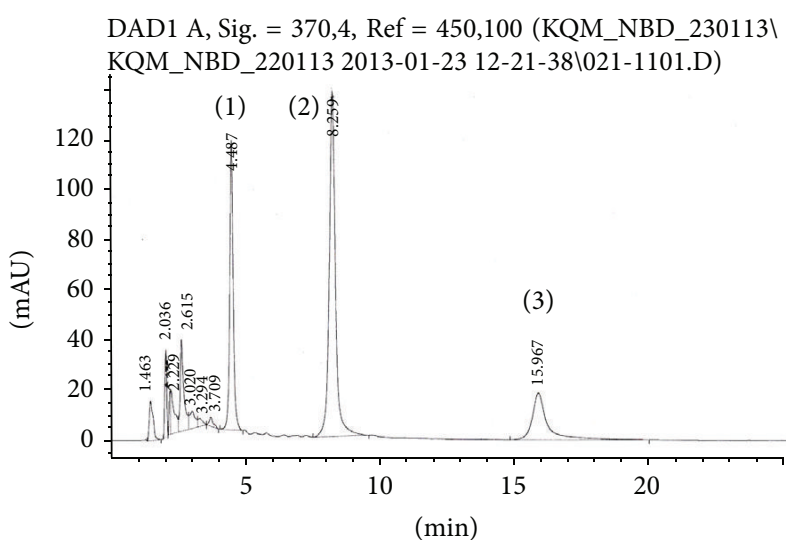

(1) Myricetin

(2) Quercetin

(3) Kaempferol

(a)

(b)

FIGURE 1: (a) HPLC chromatogram of mixed standard solution comprising kaempferol, quercetin, and myricetin. (b) Representative tea accession quantified and resolved by HPLC.

as flavonol glycosides with a sugar residue and the most common flavonol aglycones in tea are quercetin, kaempferol, and myricetin [9].

Ceylon tea from Sri Lanka, acclaimed as the best tea in the world, has its inherent unique characteristics and reputation running over more than a century [10]. The objectives of this study were to investigate the variation in flavonol aglycones, namely, quercetin, kaempferol, and myricetin in tea (Camellia sinensis L.) accessions including beverage and nonbeverage types. Therefore, we report here the first systematic study on the flavonol content in representative accessions of the Sri Lankan tea germplasm.

\section{Materials and Methods}

2.1. Collection and Preparation of Tea Samples for Analysis. $50 \mathrm{~g}$ of tender tea shoots (two apical leaves and the bud) of 87 beverage type and 6 nonbeverage type germplasm accessions was collected in triplicate from the ex situ field gene bank of Tea Research Institute of Sri Lanka (TRI), Talawakelle (latitude $6^{\circ} 54^{\prime} \mathrm{N}$, longitude $80^{\circ} 42^{\prime} \mathrm{E}$ ), and brought to the laboratory at $4^{\circ} \mathrm{C}$. Selection criteria for germplasm accessions in this study included the attributes such as morphological variations, origins, made tea quality, and sensitivity to biotic stresses [11-13]. The tea samples were immediately stored in a $-80^{\circ} \mathrm{C}$ freezer for $6 \mathrm{~h}$ to two weeks and freeze-dried for $24 \mathrm{~h}$ (Labconco Corporation, MS, USA). The freeze-dried leaves were ground to a fine powder (passed through $500 \mu \mathrm{m}$ mesh), sealed in triple laminated aluminium foil packages, and stored at $20^{\circ} \mathrm{C}$ until biochemical analysis [14].

2.2. Extraction of Flavonols. $100 \mathrm{mg}$ of freeze-dried tea sample was hydrolysed in duplicate with $0.5 \mathrm{~mL}$ of $6 \mathrm{M} \mathrm{HCl}$ and $4.5 \mathrm{~mL}$ of $60 \%$ methanol for $2 \mathrm{~h}$ in a water bath preheated to $95^{\circ} \mathrm{C}$. Hydrolysed sample extracts were topped up to $5 \mathrm{~mL}$ with $60 \%$ methanol and filtered through $0.45 \mu \mathrm{m}$ nylon filters into HPLC vials.

2.3. Preparation of Standards and Calibration Curves. Standards of myricetin, quercetin, and kaempferol (Sigma, St. Louis, USA) were prepared in $60 \%$ methanol. Calibration curves were constructed for the individual compounds. Peak identity was also confirmed by the photodiode array UV spectra.

2.4. Quantification of Flavonols. Analysis of individual flavonols was carried out in the Agilent 1260 Infinity HPLC system comprising of solvent delivery system, quaternary pump, temperature-controlled column oven, autosampler, degasser unit and a photodiode array detector with UV detection at $370 \mathrm{~nm}$, and Open Lab/Chemstation Software system. The compounds were separated on a $4.6 \times 250 \mathrm{~mm}, 5 \mu \mathrm{m}$ particle, and reversed phase ZORBAX Eclipse Plus C 18 column (Agilent, USA) (Phenomenex Inc., USA) with a guard column made of the same material (Security-Guard, Phenomenex Inc., USA) at $30^{\circ} \mathrm{C}$. $30 \%$ HPLC grade acetonitrile in $0.025 \mathrm{M}$ potassium dihydrogen orthophosphate buffer solution adjusted to a $\mathrm{pH}$ of 2.5 with $6 \mathrm{M} \mathrm{HCl}$ was used as mobile phase at a flow rate of $1.0 \mathrm{~mL} / \mathrm{min}$. The injection volume was $10 \mu \mathrm{L}$. Quantification was carried out from the integrated peak areas of the sample against the corresponding standard graph and results were expressed on dry matter basis (Figures 1(a) and 1(b)). The dry matter contents of the freeze-dried leaves were determined in accordance with ISO1573:1980.

2.5. Statistical Analysis. The results were expressed as mean \pm SD of triplicate data. Experimental data were analysed using SAS system for Windows V 9.1 (SAS Institute Inc., NC, USA). 
2.6. Reagents. Absolute methanol (analytical reagent grade), anhydrous sodium carbonate, and acetonitrile (HPLC gradient grade) were supplied by Fisher Scientific UK; quercetin, kaempferol, and myricetin were purchased from Sigma Chemicals; and potassium dihydrogen orthophosphate and hydrochloric acid (analytical grade) were purchased from British Drug House Ltd., England.

\section{Results and Discussion}

3.1. Flavonols Content of Beverage and Nonbeverage Type Accessions. The major flavonols present in tea leaves make up $2-3 \%$ of the water-soluble solids in tea $[15,16]$. Table 1 shows the amounts of myricetin, quercetin, and kaempferol quantified in the beverage and nonbeverage type accessions of the Sri Lankan tea germplasm. These results are agreeable to a greater extend with the results reported for 3 commercial samples of green tea and 30 commercial samples of black tea [17] and those reported for 4 commercial samples of green tea and 2 commercial samples of black tea [18]. According to the mean values of flavonols, quercetin $\left(1.50 \mathrm{mg} \mathrm{g}^{-1}\right)$ is abundantly present in the beverage type accessions of the Sri Lankan tea germplasm followed by kaempferol $\left(1.31 \mathrm{mg} \mathrm{g}^{-1}\right)$ and myricetin $\left(0.94 \mathrm{mg} \mathrm{g}^{-1}\right)$. The mean value of total flavonols in 89 beverage type $C$. sinensis was $3.75 \mathrm{mg} \mathrm{g}^{-1}$.

Among beverage type accessions, the highest quercetin contents were reported in the exotic accessions: PBGT41 (3.23 $\mathrm{mgg}^{-1}$ ), followed by PBGT73, China, PBGT70, and PBGT12 whereas TRI1114 showed the lowest content $\left(0.36 \mathrm{mg} \mathrm{g}^{-1}\right)$. The highest kaempferol contents were observed in the exotic accessions PBGT61 $\left(2.21 \mathrm{mgg}^{-1}\right)$ followed by PBGT68, PBGT48, PBGT49, and PBGT70. Among the 9 exotic accessions examined, PBGT41 reported the highest myricetin content $\left(1.63 \mathrm{mgg}^{-1}\right)$ followed by PBGT49, PBGT68, PBGT70, and PBGT61 and INTRI6 recorded the lowest content $\left(0.33 \mathrm{mg} \mathrm{g}^{-1}\right)$.

Conversely, myricetin was available in trace amounts recorded in the nonbeverage type accessions except Camellia sasanqua $\left(0.37 \mathrm{mg} \mathrm{g}^{-1}\right)$ and Camellia rosaflora $\left(0.20 \mathrm{mg} \mathrm{g}^{-1}\right)$. Highest kaempferol contents were observed in Camellia japonica donkelarri and Camellia japonica Red. Camellia rosaflora has reported the highest quercetin content (3.44 $\mathrm{mg} \mathrm{g}^{-1}$ ) when considering the entire germplasm, which is higher than that of the beverage type exotic cultivar PBGT41. This special characteristic can be utilized in future germplasm studies.

The specific patterns of flavonol occurrence in plant species vary based on their synthesis and distribution in the plant organism [19]. In addition to intrinsic factors, flavonol content is strongly influenced by extrinsic factors such as variations in plant type and growth, season, climate, degree of maturity, preparation, and processing [20-24].

Several studies report varying content of flavonol in teas $[1,25,26]$. This is possibly due to the difference in tea samples used (fresh tea leaves or processed tea) and analytical methods utilized, resulting in different extraction efficiencies. According to Finger et al. [27], flavonol glycosides are not affected by polyphenol oxidase and varying content in different tea types can be due to difference in tea varieties, geographic location, or agricultural conditions.

3.2. Health Aspects of Tea Flavonols. The increasing knowledge on functional ingredients in food provides new opportunities for plant sciences to produce crops with higher amounts of selected health-promoting phytochemicals using crop husbandry techniques, plant breeding techniques, and genetic engineering [28]. Recent studies suggest that higher intakes of flavonoids from food are associated with reduced risk of degenerative diseases including cancer and heart disease $[29,30]$.

The three flavonols, that is, myricetin, quercetin, and kaempferol, quantified in this study have also been extensively investigated for their health benefits. Flavonols naturally occur as either glycosides (with attached glycosyl groups) or aglycones. However, dietary intake of the above flavonols is mainly in the glycoside form. During digestion and absorption sugar moieties can be released from the glycosides. Digestive tract microbiota could also assist in the digestion and the absorption process of the flavonols. Following absorption several organs contribute to flavonol metabolism including the liver, giving rise to glucuronidated, methylated, and sulfated forms of flavonols which are found in the plasma. Further, free flavonols (aglycone) are also found in the plasma. These circulating flavonols and their metabolites have diverse biological activities [31].

Several mechanisms of actions such as antioxidant activity, anti-inflammatory activity, and modulation of signaling pathways are responsible for the beneficial effects of flavonols [32].

Prolonged oxidative stress could lead to several degenerative diseases including cardiovascular disease. Ability of hydrogen radical donation from the phenolic group and the presence of an unpaired electron in the aromatic ring make the flavonols strong antioxidants in vivo, thus scavenging the reactive oxygen species and other free radicals. Ability to chelate metal ions also reduces the production of harmful oxidant species in vivo [33]. Flavonols could contribute to the antioxidant properties through the protection or improvement of endogenous antioxidants especially by stimulating glutathione-S-transferase (GST), an enzyme that protects cells from the damage caused by free radicals [34].

The inflammatory response is part of the innate immune response which triggers the inflammatory cascade forming inflammatory mediators such as prostaglandin and thromboxane. Although acute inflammation is essential in dealing with invading pathogens and injury, chronic inflammation can cause tissue destruction and is involved in the pathogenesis of degenerative diseases. Commercially available anti-inflammatory drugs are used to prevent the formation of prostaglandins and thromboxanes by inhibiting the cyclooxygenase (COX) enzymes involved in the production of the above during inflammation. Flavonoids can suppress the expression of the COX gene through interactions with cell signaling pathways, such as the protein kinase $C, N F-\kappa B$, and tyrosine kinase pathways [35].

It has been reported that flavonols including myricetin, quercetin, and kaempferol could play an important role in 
TABLE 1: Flavonol content of Sri Lankan tea accessions (all units are in $\mathrm{mg} \mathrm{g}^{-1}$; data represent the mean of six replicates \pm standard error).

\begin{tabular}{|c|c|c|c|c|c|}
\hline Accessions & & Myricetin $\left(\mathrm{mg} \mathrm{g}^{-1}\right)$ & Quercetin $\left(\mathrm{mg} \mathrm{g}^{-1}\right)$ & Kaempferol $\left(\mathrm{mg} \mathrm{g}^{-1}\right)$ & Total flavonols $\left(\mathrm{mg} \mathrm{g}^{-1}\right)$ \\
\hline & Estate selections & & & & \\
\hline 1 & B275 & $0.54 \pm 0.08$ & $0.85 \pm 0.06$ & $0.90 \pm 0.06$ & $2.29 \pm 0.19$ \\
\hline 2 & $\mathrm{CH} 13$ & $0.92 \pm 0.10$ & $1.11 \pm 0.11$ & $2.19 \pm 0.12$ & $4.22 \pm 0.69$ \\
\hline 3 & CV4B1 & $0.56 \pm 0.06$ & $0.91 \pm 0.08$ & $1.58 \pm 0.23$ & $3.05 \pm 0.52$ \\
\hline 4 & CY9 & $1.68 \pm 0.17$ & $1.69 \pm 0.11$ & $1.70 \pm 0.16$ & $5.07 \pm 0.01$ \\
\hline 5 & DEL40 & $0.46 \pm 0.02$ & $1.37 \pm 0.01$ & $1.48 \pm 0.06$ & $3.31 \pm 0.56$ \\
\hline 6 & DG39 & $1.08 \pm 0.12$ & $2.09 \pm 0.11$ & $1.34 \pm 0.18$ & $4.51 \pm 0.53$ \\
\hline 7 & DG7 & $0.69 \pm 0.18$ & $0.43 \pm 0.04$ & $1.05 \pm 0.09$ & $2.17 \pm 0.31$ \\
\hline 8 & DK24 & $0.75 \pm 0.01$ & $2.42 \pm 0.11$ & $1.33 \pm 0.09$ & $4.50 \pm 0.85$ \\
\hline 9 & $\mathrm{DN}$ & $0.85 \pm 0.32$ & $1.17 \pm 0.30$ & $0.73 \pm 0.11$ & $2.75 \pm 0.23$ \\
\hline 10 & DT1 & $1.09 \pm 0.04$ & $2.04 \pm 0.18$ & $0.60 \pm 0.05$ & $3.74 \pm 0.73$ \\
\hline 11 & DT95 & $0.88 \pm 0.11$ & $0.92 \pm 0.12$ & $2.69 \pm 0.09$ & $4.49 \pm 1.03$ \\
\hline 12 & DUN7 & $0.99 \pm 0.06$ & $1.90 \pm 0.52$ & $1.43 \pm 0.08$ & $4.33 \pm 0.46$ \\
\hline 13 & $\mathrm{H} 1 / 58$ & $0.45 \pm 0.04$ & $0.71 \pm 0.04$ & $1.24 \pm 0.15$ & $2.41 \pm 0.40$ \\
\hline 14 & HS10A & $0.81 \pm 0.11$ & $1.07 \pm 0.02$ & $1.51 \pm 0.29$ & $3.39 \pm 0.35$ \\
\hline 15 & $\mathrm{~K} 145$ & $1.08 \pm 0.07$ & $1.29 \pm 0.51$ & $1.48 \pm 0.79$ & $3.86 \pm 0.20$ \\
\hline 16 & KEN16/3 & $0.92 \pm 0.08$ & $0.78 \pm 0.16$ & $1.46 \pm 0.15$ & $3.16 \pm 0.36$ \\
\hline 17 & KP204 & $1.22 \pm 0.17$ & $2.43 \pm 0.07$ & $0.84 \pm 0.10$ & $4.50 \pm 0.83$ \\
\hline 18 & MO241 & $0.60 \pm 0.03$ & $1.02 \pm 0.13$ & $1.47 \pm 0.10$ & $3.08 \pm 0.44$ \\
\hline 19 & MT18 & $1.85 \pm 0.95$ & $1.76 \pm 0.04$ & $1.19 \pm 0.04$ & $4.81 \pm 0.36$ \\
\hline 20 & $\mathrm{~N} 2$ & $1.12 \pm 0.12$ & $1.69 \pm 0.09$ & $1.06 \pm 0.21$ & $3.87 \pm 0.35$ \\
\hline 21 & NAY3 & $1.52 \pm 0.05$ & $2.01 \pm 0.05$ & $1.22 \pm 0.10$ & $4.76 \pm 0.40$ \\
\hline 22 & NL8/3 & $1.35 \pm 0.08$ & $1.71 \pm 0.07$ & $0.73 \pm 0.28$ & $3.79 \pm 0.50$ \\
\hline 23 & PK2 & $1.31 \pm 0.18$ & $1.96 \pm 0.17$ & $0.98 \pm 0.15$ & $4.25 \pm 0.49$ \\
\hline 24 & PLLG2 & $0.74 \pm 0.11$ & $1.06 \pm 0.12$ & $1.92 \pm 0.03$ & $3.72 \pm 0.61$ \\
\hline 25 & PO26 & $0.50 \pm 0.07$ & $0.63 \pm 0.02$ & $1.36 \pm 0.10$ & $2.48 \pm 0.46$ \\
\hline 26 & QT4/4 & $1.10 \pm 0.03$ & $1.14 \pm 0.03$ & $1.46 \pm 0.02$ & $3.69 \pm 0.20$ \\
\hline 27 & S106 & $0.91 \pm 0.01$ & $0.73 \pm 0.03$ & $1.60 \pm 0.02$ & $3.24 \pm 0.46$ \\
\hline 28 & TC10 & $0.86 \pm 0.07$ & $1.75 \pm 0.09$ & $1.73 \pm 0.08$ & $4.34 \pm 0.51$ \\
\hline 29 & TC9 & $1.48 \pm 0.14$ & $1.68 \pm 0.18$ & $1.87 \pm 0.02$ & $5.03 \pm 0.19$ \\
\hline 30 & TRI1114 & $0.64 \pm 0.06$ & $0.36 \pm 0.10$ & $0.45 \pm 0.03$ & $1.45 \pm 0.14$ \\
\hline 31 & TRI1294 & $0.93 \pm 0.07$ & $1.40 \pm 0.25$ & $2.10 \pm 0.44$ & $4.43 \pm 0.59$ \\
\hline 32 & TRI2142 & $0.78 \pm 0.04$ & $1.67 \pm 0.22$ & $1.34 \pm 0.23$ & $3.79 \pm 0.45$ \\
\hline 33 & TRI26 & $1.06 \pm 0.06$ & $1.53 \pm 0.15$ & $2.14 \pm 0.29$ & $4.73 \pm 0.54$ \\
\hline 34 & TRI3011 & $0.67 \pm 0.13$ & $1.25 \pm 0.07$ & $0.69 \pm 0.13$ & $2.60 \pm 0.33$ \\
\hline 35 & W3 & $0.79 \pm 0.10$ & $0.98 \pm 0.22$ & $1.46 \pm 0.21$ & $3.23 \pm 0.35$ \\
\hline 36 & WT26 & $0.70 \pm 0.18$ & $0.85 \pm 0.02$ & $1.26 \pm 0.12$ & $2.81 \pm 0.29$ \\
\hline 37 & TRI2016 & $0.61 \pm 0.08$ & $0.55 \pm 0.07$ & $0.67 \pm 0.09$ & $1.84 \pm 0.06$ \\
\hline & Introductions from Assam & & & & \\
\hline 38 & ASM $4 / 10$ & $0.76 \pm 0.06$ & $1.08 \pm 0.13$ & $1.01 \pm 0.06$ & $2.85 \pm 0.17$ \\
\hline 39 & TRI2022 & $1.81 \pm 0.10$ & $2.12 \pm 0.53$ & $0.63 \pm 0.10$ & $4.56 \pm 0.79$ \\
\hline 40 & TRI2023 & $1.35 \pm 0.05$ & $1.59 \pm 0.26$ & $0.79 \pm 0.09$ & $3.74 \pm 0.41$ \\
\hline 41 & TRI2024 & $0.68 \pm 0.08$ & $0.63 \pm 0.05$ & $1.09 \pm 0.20$ & $2.40 \pm 0.25$ \\
\hline 42 & TRI2025 & $0.40 \pm 0.04$ & $0.59 \pm 0.15$ & $0.99 \pm 0.06$ & $1.99 \pm 0.30$ \\
\hline 43 & TRI2026 & $0.79 \pm 0.17$ & $0.94 \pm 0.07$ & $0.87 \pm 0.11$ & $2.60 \pm 0.08$ \\
\hline 44 & TRI3047 & $0.59 \pm 0.02$ & $1.30 \pm 0.59$ & $0.83 \pm 0.14$ & $2.73 \pm 0.36$ \\
\hline 45 & TRI3055 & $1.05 \pm 0.06$ & $2.42 \pm 0.15$ & $1.07 \pm 0.06$ & $4.54 \pm 0.79$ \\
\hline 46 & TRI62/5 & $0.67 \pm 0.06$ & $1.03 \pm 0.01$ & $0.87 \pm 0.16$ & $2.57 \pm 0.18$ \\
\hline 47 & TRI62/9 & $0.44 \pm 0.04$ & $0.40 \pm 0.05$ & $0.18 \pm 0.03$ & $1.02 \pm 0.14$ \\
\hline & Introductions from Indo-China & & & & \\
\hline 48 & TRI777 & $0.65 \pm 0.05$ & $1.75 \pm 0.13$ & $1.34 \pm 0.23$ & $3.74 \pm 0.56$ \\
\hline 49 & TRI2043 & $0.83 \pm 0.05$ & $1.50 \pm 0.64$ & $0.89 \pm 0.02$ & $3.21 \pm 0.38$ \\
\hline
\end{tabular}


TABle 1: Continued.

\begin{tabular}{|c|c|c|c|c|c|}
\hline Accessions & & Myricetin $\left(\mathrm{mg} \mathrm{g}^{-1}\right)$ & Quercetin $\left(\mathrm{mg} \mathrm{g}^{-1}\right)$ & Kaempferol $\left(\mathrm{mg} \mathrm{g}^{-1}\right)$ & Total flavonols $\left(\mathrm{mg} \mathrm{g}^{-1}\right)$ \\
\hline & Unknown introductions & & & & \\
\hline 50 & INTRI6 & $0.33 \pm 0.04$ & $0.41 \pm 0.07$ & $1.14 \pm 0.13$ & $1.87 \pm 0.45$ \\
\hline \multirow[t]{2}{*}{51} & VHMOR & $0.91 \pm 0.15$ & $1.52 \pm 0.07$ & $1.64 \pm 0.21$ & $4.07 \pm 0.39$ \\
\hline & Half-sib family & & & & \\
\hline 52 & TRI3013 & $0.48 \pm 0.04$ & $0.75 \pm 0.11$ & $0.81 \pm 0.12$ & $2.05 \pm 0.18$ \\
\hline 53 & TRI3014 & $0.82 \pm 0.04$ & $2.22 \pm 0.03$ & $1.84 \pm 0.04$ & $4.88 \pm 0.72$ \\
\hline 54 & TRI3015 & $1.16 \pm 0.08$ & $1.64 \pm 0.05$ & $1.39 \pm 0.03$ & $4.19 \pm 0.24$ \\
\hline 55 & TRI3041 & $1.28 \pm 0.06$ & $2.33 \pm 0.36$ & $2.16 \pm 0.53$ & $5.76 \pm 0.56$ \\
\hline 56 & TRI3050 & $1.34 \pm 0.10$ & $1.84 \pm 0.12$ & $1.44 \pm 0.02$ & $4.61 \pm 0.26$ \\
\hline 57 & TRI3072 & $0.88 \pm 0.09$ & $1.51 \pm 0.25$ & $1.30 \pm 0.07$ & $3.69 \pm 0.32$ \\
\hline 58 & TRI3073 & $0.79 \pm 0.08$ & $1.51 \pm 0.21$ & $1.92 \pm 0.38$ & $4.22 \pm 0.57$ \\
\hline \multirow[t]{2}{*}{59} & TRI3045 & $0.92 \pm 0.18$ & $0.84 \pm 0.12$ & $1.08 \pm 0.19$ & $2.84 \pm 0.13$ \\
\hline & Full-sib family & & & & \\
\hline 60 & TRI3016 & $0.59 \pm 0.06$ & $2.15 \pm 0.18$ & $1.67 \pm 0.25$ & $4.41 \pm 0.80$ \\
\hline 61 & TRI3017 & $0.96 \pm 0.06$ & $2.04 \pm 0.14$ & $2.47 \pm 0.33$ & $5.47 \pm 0.78$ \\
\hline 62 & TRI3018 & $0.81 \pm 0.09$ & $1.71 \pm 0.02$ & $1.16 \pm 0.10$ & $3.68 \pm 0.45$ \\
\hline 63 & TRI3019 & $1.09 \pm 0.10$ & $1.92 \pm 0.28$ & $1.13 \pm 0.07$ & $4.15 \pm 0.47$ \\
\hline 64 & TRI3026 & $0.63 \pm 0.02$ & $0.81 \pm 0.06$ & $0.83 \pm 0.07$ & $2.27 \pm 0.11$ \\
\hline 65 & TRI3036 & $0.40 \pm 0.05$ & $0.89 \pm 0.21$ & $1.20 \pm 0.16$ & $2.48 \pm 0.40$ \\
\hline 66 & TRI4004 & $0.93 \pm 0.10$ & $2.00 \pm 0.04$ & $2.26 \pm 0.03$ & $5.18 \pm 0.71$ \\
\hline 67 & TRI4049 & $0.84 \pm 0.07$ & $1.23 \pm 0.27$ & $1.39 \pm 0.13$ & $3.45 \pm 0.28$ \\
\hline 68 & TRI4052 & $0.78 \pm 0.12$ & $1.14 \pm 0.06$ & $1.47 \pm 0.20$ & $3.39 \pm 0.35$ \\
\hline 69 & TRI4053 & $0.45 \pm 0.03$ & $0.94 \pm 0.11$ & $0.93 \pm 0.10$ & $2.32 \pm 0.28$ \\
\hline 70 & TRI4061 & $1.70 \pm 0.05$ & $2.27 \pm 0.31$ & $2.24 \pm 0.12$ & $6.21 \pm 0.32$ \\
\hline 71 & TRI4063 & $0.63 \pm 0.04$ & $1.42 \pm 0.04$ & $1.27 \pm 0.22$ & $3.32 \pm 0.42$ \\
\hline 72 & TRI4067 & $0.98 \pm 0.19$ & $1.02 \pm 0.22$ & $1.26 \pm 0.07$ & $3.26 \pm 0.15$ \\
\hline 73 & TRI4068 & $0.78 \pm 0.05$ & $0.64 \pm 0.18$ & $1.13 \pm 0.10$ & $2.55 \pm 0.26$ \\
\hline 74 & TRI4071 & $0.76 \pm 0.12$ & $1.10 \pm 0.17$ & $1.30 \pm 0.13$ & $3.16 \pm 0.28$ \\
\hline 75 & TRI4076 & $1.62 \pm 0.07$ & $1.91 \pm 0.12$ & $0.74 \pm 0.08$ & $4.27 \pm 0.61$ \\
\hline 76 & TRI4078 & $1.00 \pm 0.08$ & $1.33 \pm 0.16$ & $1.55 \pm 0.04$ & $3.88 \pm 0.28$ \\
\hline 77 & TRI4079 & $0.91 \pm 0.07$ & $1.37 \pm 0.08$ & $1.16 \pm 0.06$ & $3.44 \pm 0.23$ \\
\hline 78 & TRI4085 & $1.27 \pm 0.09$ & $1.15 \pm 0.24$ & $0.90 \pm 0.06$ & $3.31 \pm 0.19$ \\
\hline \multirow[t]{2}{*}{79} & TRI3022 & $1.48 \pm 0.05$ & $1.95 \pm 0.06$ & $2.19 \pm 0.11$ & $5.63 \pm 0.36$ \\
\hline & Exotics types & & & & \\
\hline 80 & China & $0.85 \pm 0.10$ & $2.98 \pm 0.21$ & $1.02 \pm 0.12$ & $4.85 \pm 1.19$ \\
\hline 81 & PBGT61 & $1.34 \pm 0.02$ & $1.70 \pm 0.03$ & $2.21 \pm 0.17$ & $5.24 \pm 0.44$ \\
\hline 82 & PBGT68 & $1.42 \pm 0.08$ & $2.39 \pm 0.07$ & $1.63 \pm 0.06$ & $5.44 \pm 0.51$ \\
\hline 83 & PBGT48 & $1.31 \pm 0.13$ & $2.34 \pm 0.10$ & $1.41 \pm 0.05$ & $5.06 \pm 0.57$ \\
\hline 84 & PBGT49 & $1.46 \pm 0.14$ & $2.41 \pm 0.08$ & $1.23 \pm 0.04$ & $5.10 \pm 0.63$ \\
\hline 85 & PBGT12 & $1.15 \pm 0.83$ & $2.61 \pm 0.28$ & $1.05 \pm 0.15$ & $4.81 \pm 0.88$ \\
\hline 86 & PBGT41 & $1.40 \pm 0.56$ & $3.23 \pm 0.39$ & $1.03 \pm 0.08$ & $5.66 \pm 1.17$ \\
\hline 87 & PBGT70 & $1.39 \pm 0.15$ & $2.85 \pm 0.15$ & $1.21 \pm 0.03$ & $5.45 \pm 0.90$ \\
\hline 88 & PBGT73 & $0.96 \pm 0.07$ & $3.05 \pm 0.04$ & $1.02 \pm 0.09$ & $5.03 \pm 1.19$ \\
\hline \multirow[t]{3}{*}{89} & Yabukita & $1.11 \pm 0.17$ & $2.12 \pm 0.03$ & $1.94 \pm 0.09$ & $5.17 \pm 0.54$ \\
\hline & Mean $(n=89)$ & 0.94 & 1.50 & 1.31 & 3.75 \\
\hline & Nonbeverage types & & & & \\
\hline 90 & C. sasanqua & $0.37 \pm 0.05$ & $1.59 \pm 0.17$ & $0.52 \pm 0.03$ & $2.48 \pm 0.67$ \\
\hline 91 & C. japonica donkelarri & ND & $1.13 \pm 0.02$ & $2.08 \pm 0.06$ & $3.21 \pm 1.04$ \\
\hline 92 & C. japonica herculea & ND & $1.96 \pm 0.18$ & $0.95 \pm 0.09$ & $2.91 \pm 0.98$ \\
\hline 93 & C. japonica Red & ND & $1.36 \pm 0.07$ & $2.02 \pm 0.05$ & $3.38 \pm 1.03$ \\
\hline 94 & C. japonica White & ND & $1.70 \pm 0.07$ & $1.60 \pm 0.06$ & $3.31 \pm 0.96$ \\
\hline \multirow[t]{2}{*}{95} & C. rosaflora & $0.20 \pm 0.00$ & $3.44 \pm 0.03$ & $1.03 \pm 0.08$ & $4.67 \pm 1.77$ \\
\hline & Mean $(n=6)$ & 0.28 & 1.86 & 1.37 & 3.33 \\
\hline
\end{tabular}

ND: not detected. 
TABLE 2: Flavonols profile of three varieties of $C$. sinensis (all units are in $\mathrm{mg} \mathrm{g}^{-1}$; data represent the mean of six replicates \pm standard error).

\begin{tabular}{lcccc}
\hline Compounds & var. sinensis $(n=10)$ & var. assamica $(n=19)$ & ssp. lasiocalyx $(n=60)$ & Nonbeverage types $(n=6)$ \\
\hline Myricetin & $1.07 \pm 0.35$ & $0.86 \pm 0.26$ & $0.96 \pm 0.37$ & $0.28 \pm 0.02$ \\
Quercetin & $2.11 \pm 0.72$ & $1.44 \pm 0.56$ & $1.43 \pm 0.64$ & $1.86 \pm 0.82$ \\
Kaempferol & $1.25 \pm 0.25$ & $1.43 \pm 0.45$ & $1.30 \pm 0.52$ & $1.37 \pm 0.63$ \\
\hline Total flavonols & $4.43 \pm 0.97$ & $3.73 \pm 0.88$ & $3.69 \pm 1.18$ & $3.29 \pm 0.66$ \\
\hline
\end{tabular}

reducing the risk of cardiovascular disease, cancer, and neurodegradative and other degenerative diseases through the above-mentioned mechanisms and several other mechanisms. Several epidemiological studies also have found the beneficial effects of flavonols [36, 37]. Therefore, it could be argued that dietary items high in flavonols could be beneficial to human health.

Although flavonol glycosides can be important contributors to black tea flavour [38], these were hydrolysed by acid treatment to afford myricetin, quercetin, and kaempferol for HPLC analysis due to the fact that the dietary forms of flavonol glycosides are initially hydrolysed to aglycones at the oral cavity [39-42] and continued in the digestive tract $[5,43]$. Even during the fermentation processes the flavonoid glycosides undergo enzymatic hydrolysis and the level of flavonoid aglycones increase. However the chemical form of flavonol prior to and after digestion is of great importance in determining the bioavailability and bioactivity.

3.3. Utilization of Flavonol Diversity in Tea Breeding. In a single plant very large number of individual glycosides may result based on the type and number of sugar residues, together with chain branching. Some of these flavonols were quite useful for discriminating genotypes in different species. Vrhovsek et al. [44] reported that myricetin glycosides had some significant level of variability among the blueberry cultivars. This means that both the biosynthesis of the different aglycones and their conjugation with different sugars are controlled by the genotype. Another comprehensive survey of flavonol content in 100 vegetables and fruits grown in China reported that quercetin was widely distributed in edible plants species [45].

Flavonol quercetin was the main compound found in many fruits and vegetables [46]. de Vries et al. [47] explored the bioavailability of quercetin from red wine, yellow onions, and black tea and came to the conclusion that tea is a rich source of flavonols. Quercetin and kaempferol rhamnodiglucosides are characteristic compounds of Camellia sinensis. According to Finger et al. [27], black tea contains $0-0.95 \mathrm{mgg}^{-1}$ quercetin rhamnodiglucoside and $0.05-1.25 \mathrm{mg} \mathrm{g}^{-1}$ kaempferol rhamnodiglucoside. However myricetin and kaempferol were also detected in many foods including tea $[1,46,48,49]$.

Based on the records available, less than $6 \%$ of the total accessions preserved in Sri Lankan tea germplasm have been utilized in the tea breeding programmes till 1998, and utilization of tea accessions has increased up to $13.6 \%$ by the end of 2009 [50]. The lack of information regarding the genetic variation, mainly biochemical and molecular diversity of the existing population, could be one reason for underutilization of the germplasm [12].

According to present study, the lowest mean value of kaempferol content is observed for Assam introductions (Figures 2(a)-2(d)). The ranges and mean values of quercetin and myricetin for full-sib and half-sib families are much similar to the Assam introductions. Therefore, it is indicated that the TRI developed accessions have direct or indirect relationship with Assam introductions. Among the selected accessions, all exotic accessions recorded higher contents of quercetin than rest. Besides, the highest mean values of total flavonol contents were reported for exotic accessions. These results revealed that those exotic accessions are having different geographic origin than other accessions present in germplasm in Sri Lanka.

3.4. Variations in Flavonols among Varieties of C. sinensis. Average values of the flavonols of China type (var. sinensis), Assam type (var. assamica), and Cambod type (ssp. lasiocalyx) of C. sinensis (L.) are given in Table 2. Flavonols, myricetin and quercetin, contents of the var. sinensis were higher than that of the var. assamica and ssp. lasiocalyx. Beside, var. assamica had the highest kaempferol content than other varieties and nonbeverage types. Among all three varieties and nonbeverage types, var. sinensis showed the highest total flavonols. Sri Lankan germplasm collection was predominantly represented by ssp. lasiocalyx followed by assamica and sinensis varieties. Around $83 \%$ of the introductions acquired prior to the 1960s, mainly from India and IndoChina, exhibit predominant Cambod type (ssp. lasiocalyx) characters and introductions made in 21st century from Korea reminiscent of more affinity to China type (var. sinensis). However, China type accessions are inadequately represented in the collection [51]. Therefore, flavonols and their glycosides can be useful to chemotaxonomic studies of tea germplasm.

As evident from the present work, the 9 exotic accessions with different geographic origin selected for this study along with the nonbeverage type accessions, especially Camellia rosaflora and Camellia japonica Red, are worthwhile and thus merit focus in future germplasm studies. The contents of myricetin and myricetin glycosides are less in black tea; unlikely, in fresh tea, they flush since they can still be affected by tea processing. Myricetin and myricetin glycosides are the most likely of the three flavonols to be oxidised [52]. However the presence of myricetin is higher in tea compared to other 


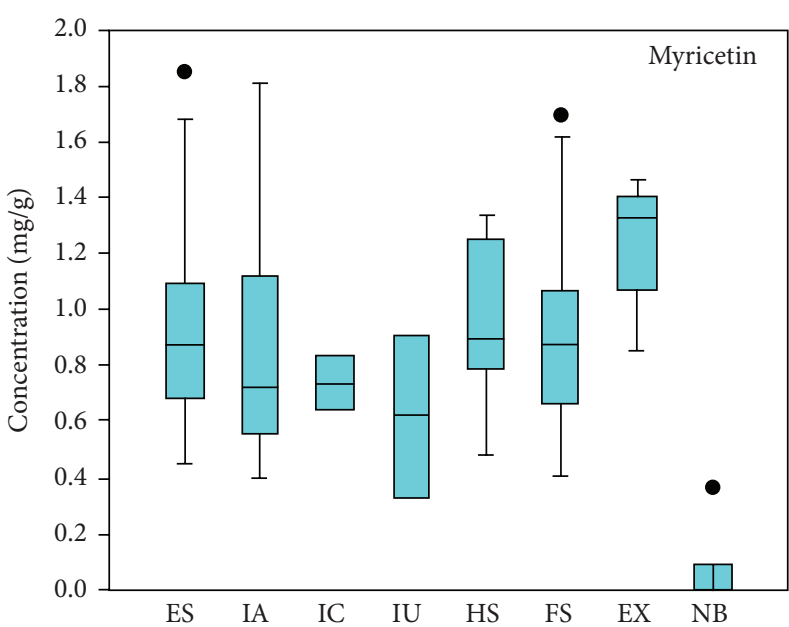

(a)

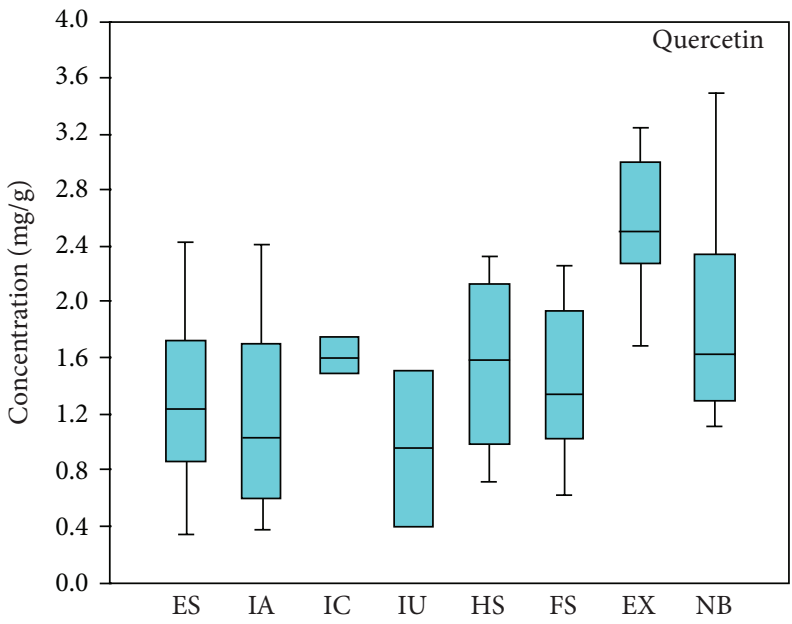

(c)

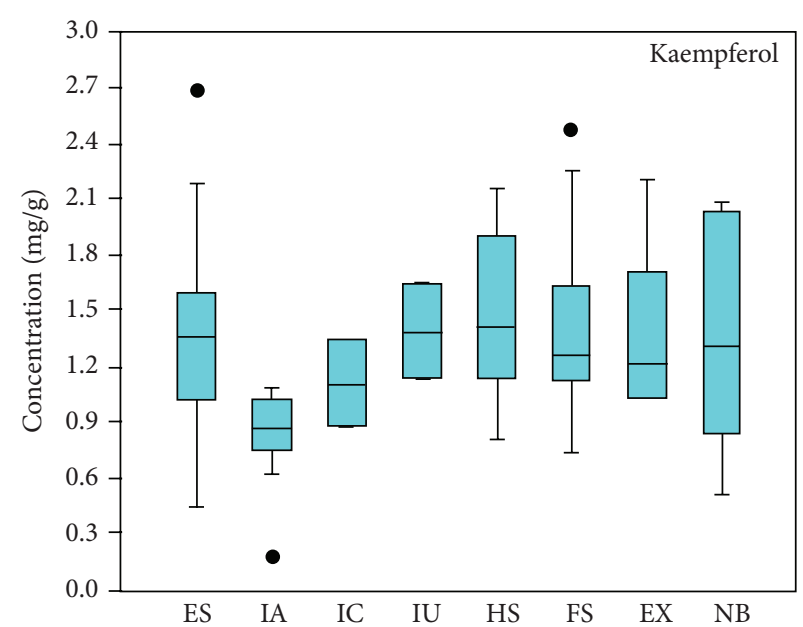

(b)

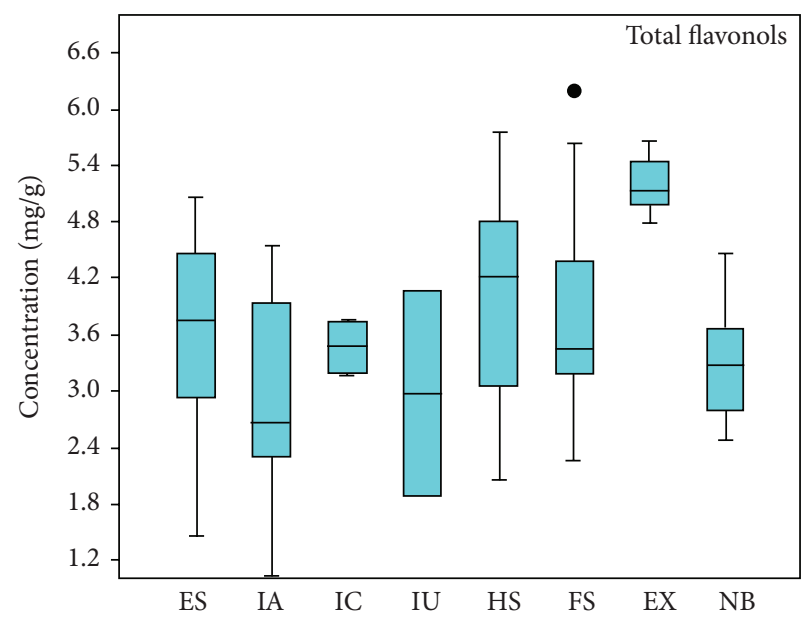

(d)

FIGURE 2: Distribution of total and individual flavonols in cultivated Camellia sinensis varieties and nonbeverage types (ES: estate selections; IA: introductions from Assam; IC: introductions from Indo-China; IU: unknown introductions; HS: half-sib families; FS: full-sib families; EX: exotic varieties; NB: nonbeverage types; and $\bullet$ indicates outliers).

herbal plants [18]. Therefore it is crucial to focus on myricetin while discussing the flavonol content of tea.

\section{Conclusions}

Significant amounts of myricetin, quercetin, and kaempferol have been quantified in the beverage type tea accessions of the Sri Lankan tea germplasm. The var. sinensis showed higher content of myricetin, quercetin, and total flavonol than var. assamica and ssp. Lasiocalyx; therefore flavonols and their glycosides can be useful to chemotaxonomic studies of tea germplasm. The nonbeverage type cultivars, especially Camellia rosaflora and Camellia japonica Red along with the exotic accessions resembling China type, are worthwhile in future germplasm studies because they are rich sources of flavonols, namely, quercetin and kaempferol, which are potent antioxidants and health-promoting aspects. Additionally, the flavonol profiles can be effectively used in choosing accessions in tea breeding programmes to generate progenies with wide variations.

\section{Competing Interests}

The authors declare that there is no conflict of interests regarding the publication of this paper.

\section{Acknowledgments}

This work was supported by the National Research Council of Sri Lanka (Grant no. NRC/11/023).

\section{References}

[1] M. G. L. Hertog, P. C. H. Hollman, and B. Van de Putte, "Content of potentially anticareinogenic flavonoids of tea infusions, wines, and fruit juices," Journal of Agricultural and Food Chemistry, vol. 41, no. 8, pp. 1242-1246, 1993. 
[2] H. M. Merken and G. R. Beecher, "Liquid chromatographic method for the separation and quantification of prominent flavonoid aglycones," Journal of Chromatography A, vol. 897, no. 1-2, pp. 177-184, 2000.

[3] N. J. Temple and K. K. Gladwin, "Fruit, vegetables, and the prevention of cancer: research challenges," Nutrition, vol. 19, no. 5, pp. 467-470, 2003.

[4] C. A. Rice-Evans and N. J. Miller, "Structure-antioxidant activity relationships of flavonoids and isoflavonoids," in Flavonoids in Health and Disease, C. A. Rice-Evans and L. Parker, Eds., pp. 199-219, Marcel Dekker, New York, NY, USA, 1998.

[5] P. C. H. Hollman, J. H. M. de Vries, S. D. van Leeuwen, M. J. B. Mengelers, and M. B. Katan, "Absorption of dietary quercetin glycosides and quercetin in healthy ileostomy volunteers," The American Journal of Clinical Nutrition, vol. 62, no. 6, pp. 12761282, 1995.

[6] I. E. Dreosti, M. J. Wargovich, and C. S. Yang, "Inhibition of carcinogenesis by tea: the evidence from experimental studies," Critical Reviews in Food Science and Nutrition, vol. 37, no. 8, pp. 761-770, 1997.

[7] L. Jie, D. Lingliang, W. Chunyan, and X. Hairong, "Flavonols in tea (Camellia sinensis) and its impact on sensory quality," Journal of Tea, vol. 36, no. 1, pp. 14-18, 2010.

[8] S. A. Wiseman, D. A. Balentine, and B. Frei, "Antioxidants in tea," Critical Reviews in Food Science and Nutrition, vol. 37, no. 8, pp. 705-718, 1997.

[9] L. H. Yao, Y. M. Jiang, J. Shi et al., "Flavonoids in food and their health benefits," Plant Foods for Human Nutrition, vol. 59, no. 3, pp. 113-122, 2004.

[10] W. W. D. Modder and A. M. T. Amarakoon, Tea and Health, Tea Research Institute, Talawakelle, Sri Lanka, 2002.

[11] J. D. Kottawa-Arachchi, M. T. K. Gunasekare, M. A. B. Ranatunga, P. A. N. Punyasiri, L. Jayasinghe, and R. P. Karunagoda, "Biochemical characteristics of tea (Camellia L. spp.) germplasm accessions in Sri Lanka: correlation between black tea quality parameters and organoleptic evaluation," International Journal of Tea Science, vol. 10, no. 1, pp. 3-13, 2014.

[12] J. D. Kottawa-Arachchi, M. T. K. Gunasekare, M. A. B. Ranatunga, P. A. N. Punyasiri, and L. Jayasinghe, "Use of biochemical compounds in tea germplasm characterization and its implications in tea breeding in Sri Lanka," Journal of the National Science Foundation of Sri Lanka, vol. 41, no. 4, pp. 309318, 2013.

[13] J. H. N. Piyasundara, M. T. K. Gunasekare, and I. P. Wickramasinghe, "Characterization of tea (Camellia sinensis L.) germplasm in Sri Lanka using morphological descriptors," Sri Lanka Journal of Tea Science, vol. 74, no. 1, pp. 31-39, 2009.

[14] P. A. N. Punyasiri, B. Jeganathan, J. D. Kottawa-Arachchi et al., "New sample preparation method for quantification of phenolic compounds of tea (Camellia sinensis L. Kuntze): a polyphenol rich plant," Journal of Analytical Methods in Chemistry, vol. 2015, Article ID 964341, 6 pages, 2015.

[15] Q. K. Cheng and Z. M. Chen, Tea and Health, Press of Chinese Agricultural Sciences, Beijing, China, 1994.

[16] D. A. Balentine, S. A. Wiseman, and L. C. M. Bouwens, "The chemistry of tea flavonoids," Critical Reviews in Food Science and Nutrition, vol. 37, no. 8, pp. 693-704, 1997.

[17] J. Peterson, J. Dwyer, S. Bhagwat et al., "Major flavonoids in dry tea," Journal of Food Composition and Analysis, vol. 18, no. 6, pp. 487-501, 2005.
[18] H. Wang and K. Helliwell, "Determination of flavonols in green and black tea leaves and green tea infusions by highperformance liquid chromatography," Food Research International, vol. 34, no. 2-3, pp. 223-227, 2001.

[19] J. Kühnau, "The flavonoids. A class of semi-essential food components: their role in human nutrition," World Review of Nutrition And Dietetics, vol. 24, pp. 117-191, 1976.

[20] M. S. McDonald, M. Hughes, J. Burns, M. E. J. Lean, D. Matthews, and A. Crozier, "Survey of the free and conjugated myricetin and quercetin content of red wines of different geographical origins," Journal of Agricultural and Food Chemistry, vol. 46, no. 2, pp. 368-375, 1998.

[21] A. Trichopoulou, E. Vasilopoulou, P. Hollman et al., "Nutritional composition and flavonoid content of edible wild greens and green pies: a potential rich source of antioxidant nutrients in the Mediterranean diet," Food Chemistry, vol. 70, no. 3, pp. 319-323, 2000.

[22] C. Lakenbrink, S. Lapczynski, B. Maiwald, and U. H. Engelhardt, "Flavonoids and other polyphenols in consumer brews of tea and other caffeinated beverages," Journal of Agricultural and Food Chemistry, vol. 48, no. 7, pp. 2848-2852, 2000.

[23] A. J. Stewart, S. Bozonnet, W. Mullen, G. I. Jenkins, M. E. J. Lean, and A. Crozier, "Occurrence of flavonols in tomatoes and tomato-based products," Journal of Agricultural and Food Chemistry, vol. 48, no. 7, pp. 2663-2669, 2000.

[24] C. Ewald, S. Fjelkner-Modig, K. Johansson, I. Sjöholm, and B. Åkesson, "Effect of processing on major flavonoids in processed onions, green beans, and peas," Food Chemistry, vol. 64, no. 2, pp. 231-235, 1999.

[25] U. Justesen, P. Knuthsen, and T. Leth, "Quantitative analysis of flavonols, flavones, and flavanones in fruits, vegetables and beverages by high-performance liquid chromatography with photo-diode array and mass spectrometric detection," Journal of Chromatography A, vol. 799, no. 1-2, pp. 101-110, 1998.

[26] P. Mattila, J. Astola, and J. Kumpulainen, "Determination of flavonoids in plant material by HPLC with diode-array and electro-array detections," Journal of Agricultural and Food Chemistry, vol. 48, no. 12, pp. 5834-5841, 2000.

[27] A. Finger, U. H. Engelhardt, and V. Wray, "Flavonol glycosides in tea-kaempferol and quercetin rhamnodiglucosides," Journal of the Science of Food and Agriculture, vol. 55, no. 2, pp. 313-321, 1991.

[28] T. P. Mikkonen, K. R. Määttä, A. T. Hukkanen et al., "Flavonol content varies among black currant cultivars," Journal of Agricultural and Food Chemistry, vol. 49, no. 7, pp. 3274-3277, 2001.

[29] A. Rodriguez-Mateos, D. Vauzour, C. G. Krueger et al., "Bioavailability, bioactivity and impact on health of dietary flavonoids and related compounds: an update," Archives of Toxicology, vol. 88, no. 10, pp. 1803-1853, 2014.

[30] A. Kozłowska and D. Szostak-Wegierek, "Flavonoids-food sources and health benefits," Roczniki Państwowego Zakładu Higieny, vol. 65, no. 2, pp. 79-85, 2014.

[31] L. Marín, E. M. Miguélez, C. J. Villar, and F. Lombó, “Bioavailability of dietary polyphenols and gut microbiota metabolism: antimicrobial properties," BioMed Research International, vol. 2015, Article ID 905215, 18 pages, 2015.

[32] J. H. G. Lago, A. C. Toledo-Arruda, M. Mernak et al., "Structureactivity association of flavonoids in lung diseases," Molecules, vol. 19, no. 3, pp. 3570-3595, 2014.

[33] M. M. Silva, M. R. Santos, G. Caroço, R. Rocha, G. Justino, and L. Mira, "Structure-antioxidant activity relationships of 
flavonoids: a re-examination," Free Radical Research, vol. 36, no. 11, pp. 1219-1227, 2002.

[34] H. Fiander and H. Schneider, "Dietary ortho phenols that induce glutathione S-transferase and increase the resistance of cells to hydrogen peroxide are potential cancer chemopreventives that act by two mechanisms: the alleviation of oxidative stress and the detoxification of mutagenic xenobiotics," Cancer Letters, vol. 156, no. 2, pp. 117-124, 2000.

[35] M. L. Ferrándiz and M. J. Alcaraz, "Anti-inflammatory activity and inhibition of arachidonic acid metabolism by flavonoids," Agents and Actions, vol. 32, no. 3-4, pp. 283-288, 1991.

[36] J. J. Peterson, J. T. Dwyer, P. F. Jacques, and M. L. McCullough, "Associations between flavonoids and cardiovascular disease incidence or mortality in European and US populations," Nutrition Reviews, vol. 70, no. 9, pp. 491-508, 2012.

[37] D. F. Romagnolo and O. I. Selmin, "Flavonoids and cancer prevention: a review of the evidence," Journal of Nutrition in Gerontology and Geriatrics, vol. 31, no. 3, pp. 206-238, 2012.

[38] S. Scharbert and T. Hofmann, "Molecular definition of black tea taste by means of quantitative studies, taste reconstitution, and omission experiments," Journal of Agricultural and Food Chemistry, vol. 53, no. 13, pp. 5377-5384, 2005.

[39] I. A. Macdonald, J. A. Mader, and R. G. Bussard, "The role of rutin and quercitrin in stimulating flavonol glycosidase activity by cultured cell-free microbial preparations of human feces and saliva," Mutation Research Letters, vol. 122, no. 2, pp. 95-102, 1983.

[40] A. Laires, P. Pacheco, and J. Rueff, "Mutagenicity of rutin and the glycosidic activity of cultured cell-free microbial preparations of human faeces and saliva," Food and Chemical Toxicology, vol. 27, no. 7, pp. 437-443, 1989.

[41] S. Hirota, T. Nishioka, T. Shimoda, K. Miura, T. Ansai, and U. Takahama, "Quercetin glucosides are hydrolyzed to quercetin in human oral cavity to participate in peroxidase-dependent scavenging of hydrogen peroxide," Food Science and Technology Research, vol. 7, no. 3, pp. 239-245, 2001.

[42] T. Walle, A. M. Browning, L. L. Steed, S. G. Reed, and U. K. Walle, "Flavonoid glucosides are hydrolyzed and thus activated in the oral cavity in humans," The Journal of Nutrition, vol. 135, no. 1, pp. 48-52, 2005.

[43] V. D. Bokkenheuser, C. H. L. Shackleton, and J. Winter, "Hydrolysis of dietary flavonoid glycosides by strains of intestinal Bacteroides from humans," Biochemical Journal, vol. 248, no. 3, pp. 953-956, 1987.

[44] U. Vrhovsek, D. Masuero, L. Palmieri, and F. Mattivi, "Identification and quantification of flavonol glycosides in cultivated blueberry cultivars," Journal of Food Composition and Analysis, vol. 25, no. 1, pp. 9-16, 2012.

[45] J. Cao, W. Chen, Y. Zhang, Y. Zhang, and X. Zhao, "Content of selected flavonoids in 100 edible vegetables and fruits," Food Science and Technology Research, vol. 16, no. 5, pp. 395-402, 2010.

[46] A. Crozier, M. E. J. Lean, M. S. McDonald, and C. Black, "Quantitative analysis of the flavonoid content of commercial tomatoes, onions, lettuce and celery," Journal of Agricultural and Food Chemistry, vol. 45, no. 3, pp. 590-595, 1997.

[47] J. H. M. de Vries, P. C. H. Hollman, I. van Amersfoort, M. R. Olthof, and M. B. Katan, "Red wine is a poor source of bioavailable flavonols in men," Journal of Nutrition, vol. 131, no. 3, pp. 745-748, 2001.

[48] M. G. L. Hertog, P. C. H. Hollman, and D. P. Venema, "Optimization of a quantitative HPLC determination of potentially anticarcinogenic flavonoids in vegetables and fruits," Journal of Agricultural and Food Chemistry, vol. 40, no. 9, pp. 1591-1598, 1992.

[49] M. G. L. Hertog, P. C. H. Hollman, and M. B. Katan, "Content of potentially anticarcinogenic flavonoids of 28 vegetables and 9 fruits commonly consumed in the Netherlands," Journal of Agricultural and Food Chemistry, vol. 40, no. 12, pp. 2379-2383, 1992.

[50] M. T. K. Gunasekare, M. A. B. Ranatunga, J. H. N. Piyasundara, and J. D. Kottawa-Arachchi, "Tea genetic resources in Sri Lanka: collection, conservation and appraisal," International Journal of Tea Science, vol. 8, no. 3, pp. 51-60, 2012.

[51] M. A. B. Ranatunga, H. G. J. Kumudumali, J. D. Kottawa Arachchi, M. T. K. Gunasekere, and D. M. D. Yakandawala, "Genetic structure of tea (Camellia sinensis (L) O. Kuntze) germplasm in Sri Lanka: implication on germplasm management and tea breeding," in Proceedings of the Peradeniya University International Research Sessions, vol. 18, Peradeniya, Sri Lanka, July 2014.

[52] I. McDowell, R. G. Bailey, and G. Howard, "Flavonol glycosides in black tea," Journal of the Science of Food and Agriculture, vol. 53, no. 3, pp. 411-414, 1990. 

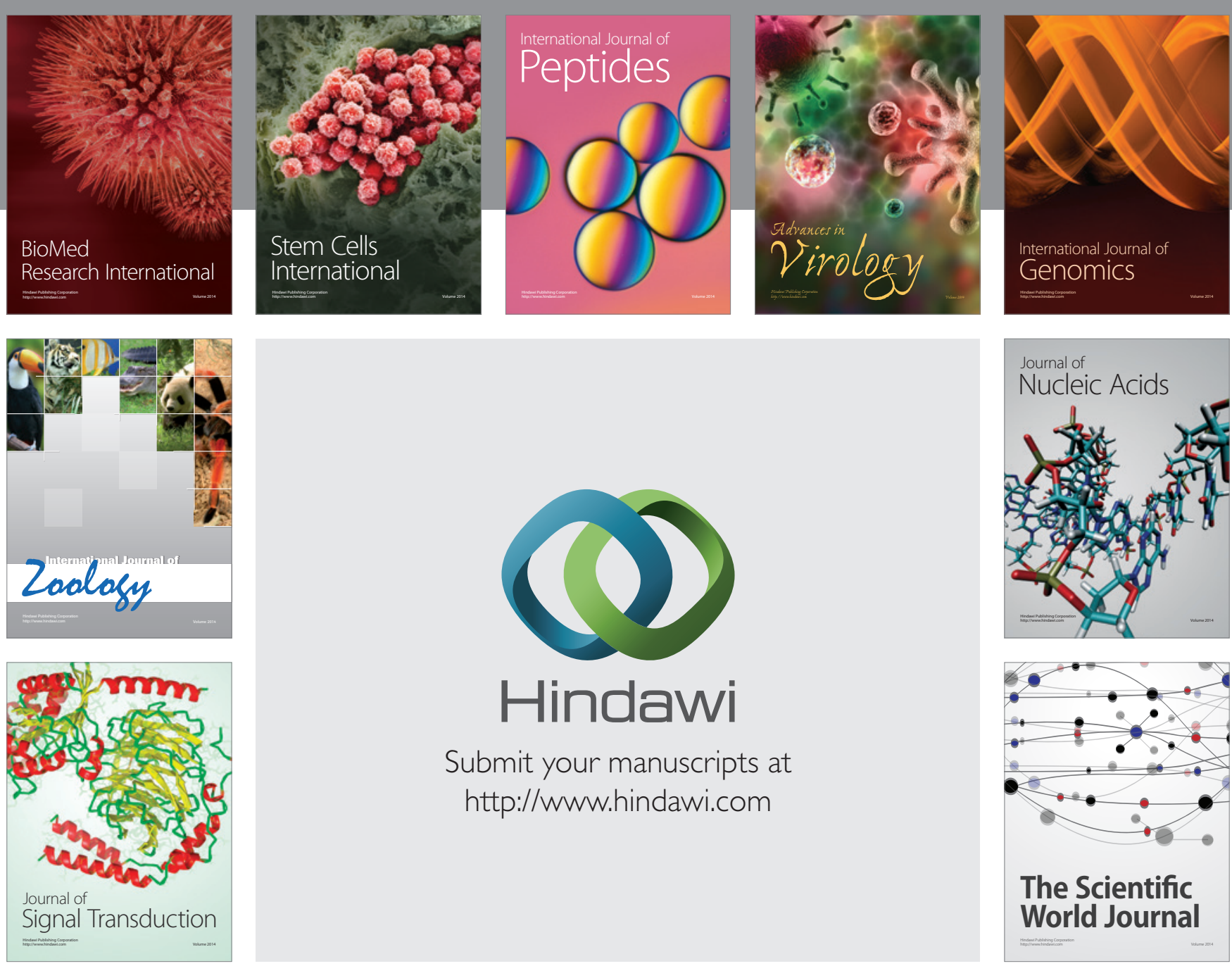

Submit your manuscripts at

http://www.hindawi.com
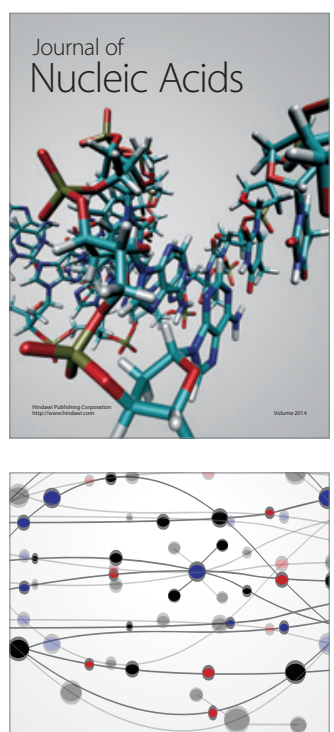

The Scientific World Journal
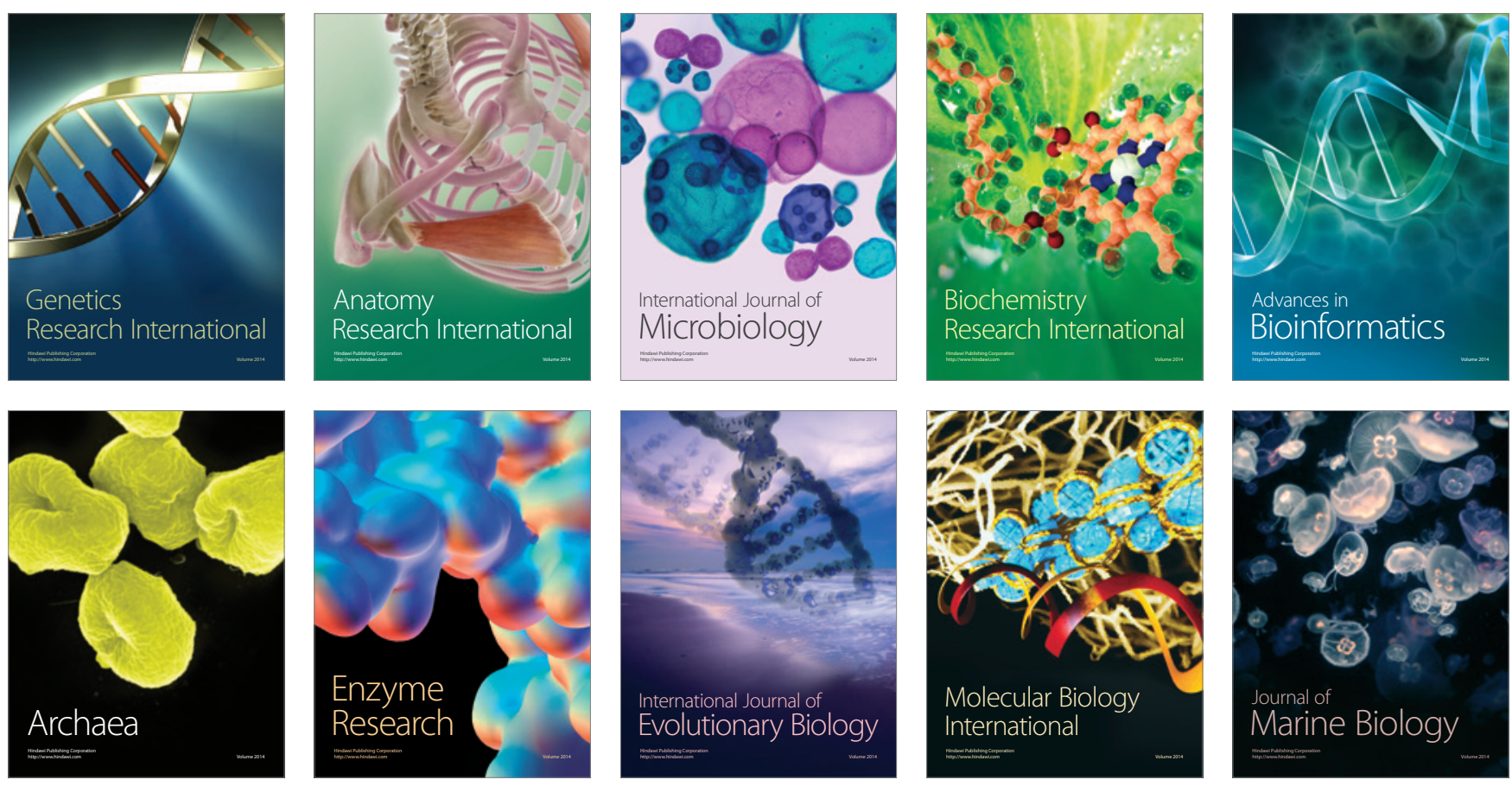